\title{
PENGUKURAN KEPRIBADIAN DAN MODELING TERHADAP PERILAKU MEROKOK REMAJA AWAL
}

\author{
Abd.Khafid Masnur \\ Fakultas Psikologi UIN Jakarta \\ Nila Tresniasari \\ Fakultas Psikologi UIN Jakarta
}

\begin{abstract}
Smoking behavior on adolescence is a worrying phenomenon. One of the factors is in their personality. Unfortunately, we don't have any standardized instrument of personality in Indonesia. Because of that, this study tested an instrument that has been used widely in other countries, HEXACO-PI-R. There are 6 dimensions of personality: honesty-humility $(H)$, emotionality $(E)$, extraversion $(X)$, agreeableness $(A)$, conscientiousness $(C)$, and openness to experience $(O)$ (Ashton \& Lee, 2007) that are measured by 60 items. Furthermore, modeling is also a predictor of smoking behavior on adolescence. Test were conducted in 2014 in Luwu Timur, South Sulawesi. 425 adolescences aged 10-12 were tested. Confirmatory Factor Analysis wer used in this study with LISREL 8.70. The result shows that all dimensions fit to measure one factor model.
\end{abstract}

Keyword: adolescence, personality. HEXACO-PI-R, modeling

\begin{abstract}
Abstrak
Perilaku merokok pada remaja di usia sekolah merupakan hal yang sangat memprihatinkan. Salah satu faktornya yaitu ada pada kepribadian remaja tersebut. Sayang di Indonesia belum memiliki satu alat ukur baku yang dapat digunakan untuk pengukuran kepribadian seseorang. Oleh karena itu, penelitian ini melakukan pengujian terhadap alat ukur yang telah banyak digunakan oleh negara-negara lain. yaitu HEXACO-PI-R. Terdapat 6 dimensi kepribadian yaitu: honesty-humility (H), emotionality (E), extraversion (X), agreeableness $(A)$, conscientiousness $(C)$, dan openness to experience (O) (Ashton \& Lee, 2007) yang diukur dengan 60 item. Selain itu, modeling juga menjadi salah satu predictor remaja untuk merokok. Pelaksanaan tes dilakukan pada tahun 2014 di Kabupaten Luwu Timur, Sulawasi Selatan. Total remaja yaitu mereka yang berusia 10-12 tahun yang menjadi responden dalam pengukuran ini adalah 425 orang. Dalam penelitian ini, metode analisis faktor yang digunakan yaitu Confirmatory Factor Analysis (CFA) dengan program lisrel 8.70. Hasilnya adalah semua dimensi fit (sesuai) mengukur model satu faktor.
\end{abstract}

Kata kunci: remaja, kepribadian, HEXACO-PI-R, modeling 


\section{PENDAHULUAN}

Usia remaja awal atau masa pubertas adalah masa-masa dimana seorang anak mengalami masa transisi dari masa anak menuju masa remaja, dan terjadi perubahan fisik hingga perubahan psikologis pada anak (Notoatmodjo, 2010). Pada masa ini remaja sering dihadapkan pada masalah yang kompleks yang berkaitan dengan perubahan-perubahan yang terjadi pada dirinya, sehingga remaja merasakan ketidakstabilan emosi ketika menghadapi sesuatu (Notoatmodjo, 2010). Akibatnya remaja menjadi sangat rentan terbawa arus pergaulan yang kurang baik seperti mengkonsumsi rokok, alkohol, narkoba dan lain-lain.

Data Biro Pusat Statistik (SUSENAS) menunjukkan jumlah perokok pemula usia 5-9 tahun meningkat tajam dari 0,4\% (2001) menjadi 2,8\% (2004). Trend perokok pemula pada usia 10-14 tahun pun meningkat drastis, dari 9.5\% (2001) menjadi 17.5\% (2010) (DEPKES, 2012).

Merokok sangat berbahaya bagi kesehatan jangka pendek dan jangka panjang (Wahyono \& Maharani, 2010). Selain mempengaruhi kesehatan merokok rupanya merokok juga menjadi permulaan kebiasaan buruk lainnya. Mereka yang merokok sejak dini memiliki kemungkinan lebih besar berpartisipasi dalam tindakan anarkis, menjadi alcoholic dan menjadi pelaku seks bebas pada masa perkembangan berikutnya (Fayombo, G., 2010). Hal ini dapat menjadi bom waktu untuk Indonesia, karena banyak generasi mudanya yang bukan saja terancam kesehatannya tapi juga memiliki karakter yang rusak karena kebiasaan buruk merokok.

Saat ini, bukan hanya di kota-kota besar seperti Jakarta saja kita dapat menemukan anak-anak yang merokok. Perilaku merokok di kalangan anakanak sudah dapat kita temui di beberapa Kabupaten di Kawasan Indonesia bagian Tengah. Pada penelitian ini, peneliti memilih Kabupaten Luwu Timur Provinsi Sulawesi Selatan sebagai tempat penelitian. Semakin meluasnya remaja usia sekolah yang merokok ini disebabkan oleh pengetahuan yang rendah, pergaulan, kemudahan mendapatkan rokok, dan adanya pengaruh budaya masyarakat.

Kurt Lewin (dalam Komalasari \& Helmi, 2000) berpendapat bahwa perilaku merokok merupakan fungsi dari lingkungan dan individu. Artinya, perilaku merokok selain disebabkan faktor-faktor dari dalam diri, juga disebabkan faktor lingkungan. Pembahasan kali ini berfokus pada pengaruh kepribadian terhadap perilaku merokok pada remaja usia sekolah.

Kepribadian sering kali menjadi prediktor kuat perilaku merokok. Kepribadian adalah variabel yang stabil yang sangat baik dijadikan sebagai predictor perilaku merokok (Zolnowski, 2010). Beberapa penelitian menguji pengaruh kepribadian terhadap perilaku merokok dengan menggunakan model Big-Five Factor seperti penelitian yang dilakukan oleh Malouff 
et al., (2006), Von Ah et al. (2005), Hames \& Parker (2008) dan Zolnowski (2012)yang menemukan bahwa adanya pengaruh signifikan tipe kepribadian terhadap perilaku merokok individu.

Namun dalam satu dekade terakhir, Ashton \& Lee telah mengembangkan klasifikasi kepribadian yang merevisi kekurangan dari klasifikasi big five. Yaitu klasifikasi HEXACO, yang terdiri dari 6 tipe kepribadian yaitu honesty-humility $(\mathrm{H})$, emotionality $(\mathrm{E})$, extraversion $(\mathrm{X})$, agreeableness $(\mathrm{A})$, conscientiousness $(\mathrm{C})$, dan openness to experience $(\mathrm{O})($ Ashton dan Lee, 2007). Klasifikasi kepribadian ini menghilangkan dimensi negatif dari big five yaitu neuritism dan narsism. Kepribadian dengan klasifikasi HEXACO dapat diperoleh dengan alat tes yang disebut HEXACO-PI-R. Alat ukur ini berjumlah 60 item, dengan model skala likert. Peneliti telah mengadaptasikan alat ukur tersebut dalam Bahasa Indonesia agar dapat diujikan pada remaja usia sekolah di Kabupaten Luwu Timur untuk melihat besar pengaruh kepribadian terhadap perilaku merokok.

\section{KAJIAN TOERI}

\section{Perilaku Merokok pada Remaja Usia Sekolah Dasar}

Dewasa ini rokok bukan hanya dikoknsumsi pria dewasa, namun juga banyak anak-anak dan perempuan yang mulai menghisapnya. Lebih fokusnya lagi, anak-anak yang menjadi perokok, hal ini dikarenakan pergeseran usia pubertas yang terjadi dalam beberapa dekade terakhir. Kini remaja usia Sekolah Dasar yang duduk di kelas 4, 5 dan 6 sudah banyak yang memasuki usia pubertas, usia dimana mereka mengeksplorasi diri dan mencoba sesuatu yang baru. Mereka meniru perilaku orang dewasa, termasuk perilaku merokok, agar mereka diterima oleh lingkungannya (Atmojo, 2013).

Menurut data Komnas Anak, pada tahun 1970 usia perokok termuda adalah 15 tahun, namun pada tahun 2004 usia perokok termuda adalah 7 tahun (Messwati, 2008). Hal tersebut didukung dari beberapa hasil penelitian yang menunjukkan bahwa kebiasaan merokok telah dimulai sejak anak-anak. Bahkan dari tahun ke tahun menunjukkan usia awal merokok semakin muda. Hasil riset Lembaga Menanggulangi Masalah Merokok (LM3) melaporkan bahwa anak-anak di Indonesia sudah ada yang mulai merokok pada usia 9 tahun (Komalasari \& Helmi, 2006).

Merokok adalah suatu perbuatan yang dapat merugikan diri sendiri dan orang lain yang berada di lingkungan sekitar kita. Sarafino (2011) mendefinisikan perilaku merokok sebagai perilaku individu saat membakar lintingan tembakau yang dihisap melalui pipa kecil atau langsung dengan mulut mereka. 


\section{Kepribadian terhadap Perilaku Merokok}

Kepribadian merupakan pola khas seseorang dalam berpikir, merasakan dan berperilaku yang relatif stabil dan dapat diprediksikan (Dorland, 2002). Selanjutnya definisi kepribadian menurut Allport (1961) (dalam Michel, 2003) adalah organisasi dinamis yang terdapat di dalam individu atas sistemsistem psikofisis yang menentukan penyesuaian dirinya yang khas terhadap lingkungannya.

Selanjutnya klasifikasi kepribadian, masing-masing tokoh mengembangkan teorinya dan memiliki klasifikasi yang khas, seperti klasifikasi kepribadian Eysenk, klasifikasi kepribadian Jung, big five factor model, dan yang terbaru adalah klasifikasi kepribadian HEXACO-PI-R dengan 6 tipe kepribadian. Yaitu: honesty-humility $(\mathrm{H})$, emotionality $(\mathrm{E})$, extraversion $(\mathrm{X})$, agreeableness $(\mathrm{A})$, conscientiousness $(\mathrm{C})$, dan openness to experience $(\mathrm{O})($ Ashton dan Lee, 2007). tersebut:

Berikut ini penjelasan mengenai masing-masing dimensi kepribadian

Honesty-Humility (kejujuran dan kerendahan hati) yaitu kecenderungan individu untuk bersikap adil dan tulus dalam bekerja sama, menghindari tindakan memanfaatkan orang lain demi keuntungan pribadi, tidak tergoda untuk melanggar aturan dan mudah bekerja sama serta selalu bersikap sopan. Pengaruhnya terhadap perilaku merokok belum pernah diteliti.

Emotionality (emosional) yaitu berkaitan dengan bagaimana individu mendapatkan dukungan sosial dari orang lain, tidak sebatas perasaan empati tetapi juga dapat membentuk kedekatan emosional terhadap orang lain. Pengaruhnya terhadap perilaku merokok belum pernah diteliti.

Extraversion adalah individu yang mampu menyatakan apa yang dia rasakan, mempunyai kepercayaan diri dalam memimpin sebuah kelompok dan aktif dalam bersosialisasi atau interaksi sosial. Dimana menurut penelitian yang dilakukan Zolnowski (2012) tingginya skor extroversion memiliki pengaruh yang signifikan terhadap perilaku merokok.

Agreeableness adalah individu yang mempunyai kecenderungan untuk memaafkan dan toleran terhadap orang lain, dapat bekerja sama dengan orang lain serta dapat mengendalikan emosi yang dia rasakan. Dalam penelitian yang dilakukan Zolnowski (2012), seorang perokok cenderung memiliki skor tinggi pada dimensi agreeableness.

Conscientiousness adalah individu yang mempunyai managemen waktu yang baik, bekerja dengan rajin dan tekun untuk mencapai tujuan mereka, berusaha untuk selalu sempurna dalam setiap pekerjaannya serta bijaksana dalam mengambil keputusan. Penelitian Von Ah et al., (2005), Malouff et al., (2006), Hames \& Parker (2008), dan Zolnowski (2012) membuktikan bahwa rendahnya skor conscientiousnessditemukan pada orang-orang yang merokok.

Openness to Experience adalah individu yang suka dengan keindahan, memiliki rasa ingin tahu yang tinggi, memiliki daya imajinasi yang baik serta 
dapat menciptakan hal-hal yang baru yang belum ada sebelumnya. Menurut bebrapa penelitian, bervariasinya skor kepribadian openness to experience tidak memiliki pengaruh yang signifikan terhadap perilaku merokok.

Modeling adalah proses belajar yang muncul dengan melihat perilaku orang lain yang nampak Bandura 1969 (dalam Taylor, 2009). Ormrod (2009) menjelaskan modeling adalah memperagakan sebuah perilaku untuk orang lain atau mengimitasi perilaku orang lain. Menurut J.P Chaplin (2008), modeling adalah belajar memberikan reaksi dengan jalan mengamati orang lain yang tengah mereaksi.

\section{METODOLOGI}

\section{Subjek Penelitian}

Jumlah sampel dalam penelitian ini sebanyak 425 orang anak sekolah dasar (SD) dengan usia 10-12 tahun dimana usia ini adalah tahapan anak-anak akhir. Pengambilan sampel dalam penelitian ini bersifat non-probability sampling yang berarti kemungkinan terpilihnya setiap sampel tidak melalui prosedur tertentu.

\section{Metode}

Penelitian ini memiliki variabel independen sebanyak tujuh variabel dan satu variabel dependen. Dalam penelitian ini tidak bisa dilakukan analisis regresi biasa dikarenakan variabel dependen yang digunakan dalam penelitian ini merupakan data kategorik dikotomi, sedangkan dalam analisis regresi biasa diasumsikan variabel tersebut adalah kontinum. Jika tetap dilakukan analisis regresi biasa maka hasil menjadi palsu atau tidak valid. Itulah sebabnya dalam penelitian ini peneliti menggunakan teknik analisis regresi logistik berganda untuk menguji hipotesis nihil penelitian ini. Penyelesaian ini menggunakan pendekatan persamaan non linear yaitu model logistik dengan persamaan regresi logistik sebagai berikut:

$\mathrm{f}(\mathrm{x})=p(i)=\frac{1}{1+e^{-\left(\hat{a}_{0}+\hat{a}_{1} X_{1}+\hat{a}_{2} X_{2}+\hat{a}_{8} X_{4}+\hat{a}_{5} X_{5}+\hat{a}_{6} X_{6}+\hat{a}_{7} X_{7}\right)}}$

Keterangan:

$p(i)=$ Probabilitas melakukan merokok

$e^{e}=$ basis logaritma natural, yaitu mathematical constant (2.718)

$\beta=$ koefisien regresi

$\mathrm{X}_{1}=$ Honesty-Humility

$\mathrm{X}_{2}=$ Emotionality

$\mathrm{X}_{3}=$ Extraversion

$\mathrm{X}_{4}=$ Agreebleness

$\mathrm{X}_{5}=$ Conscientiousness 
$\mathrm{X}_{6}=$ Openess to Experience

$\mathrm{X}_{7}=$ Modeling

Koefisien ini memiliki penafsiran yang sama persis dengan koefisien dalam regresi biasa namun unit variabel dependen dalam regresi logistik diwakili dengan log odds $\left(L_{i}\right)$ yang memiliki satuan logit (Pampel, 2000).

$$
L_{i}=\beta_{0}+\beta_{1} X_{1}+\beta_{2} X_{2}+\beta_{3} X_{3}+\beta_{4} X_{4}+\beta_{5} X_{5}+\beta_{6} X_{6}+\beta_{7} X_{7}
$$

di mana $L_{i}=$ Logit dari perilaku merokok.

Eksponen dari persamaan regresi logistik menghilangkan log dari odds dan menunjukkan pengaruh dari variabel pada odds $\left(O_{i}\right)$.

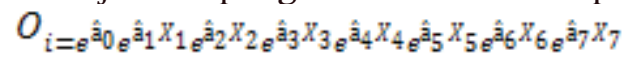

Dalam hal ini odds adalah rasio dari probabilitas melakukan perilaku merokok $\left(P_{i}\right)$ dibandingkan dengan probabilitas kejadian tidak melakukan perilaku merokok $\left(1-P_{i}\right)$, sehingga dapat dituliskan dengan rumus berikut:

$$
O_{i}=\frac{P_{i}}{1-P_{i}}
$$

di mana $O_{i}=$ odds melakukan perilaku merokok.

Terdapat sebuah rumus sederhana di dalam analisis regresi logistik yang menunjukkan OR dapat ditafsirkan sebagai persentase perubahan (percent change). Adapun rumusnya adalah sebagai berikut:

$\%$ change $=100(\mathrm{OR}-1)$.

\section{HASIL}

Tabel 4.1

Kriteria Sampel

\begin{tabular}{ccc}
\hline \hline Kriteria & N=425 & Jumlah \\
\hline $\begin{array}{c}\text { Perilaku } \\
\text { Merokok }\end{array}$ & Merokok & 225 \\
& Tidak Merokok & 200 \\
Usia & 10 Tahun & 101 \\
& 11 Tahun & 124 \\
Status & 12 Tahun & 200 \\
Merokok & Merokok & 263 \\
Ayah & Tidak Merokok & 162 \\
\hline \hline
\end{tabular}

Untuk gambaran sampel berdasarkan kecamatan yang ada di Kabupaten 
Luwu Timur dapat dilihat pada gambar 4.1

Gambar 4.1

Sampel penelitian

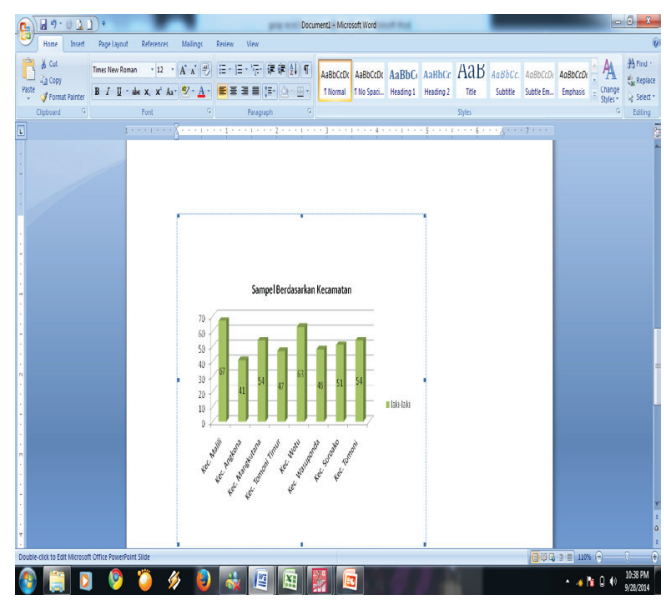

Pada tabel 4.3 digambarkan hasil statistik deskriptif dari variabel dalam penelitian ini yang berisi nilai minimum dan maksimum, nilai mean dan standar deviasi (SD) dari masing-masing variabel.

Tabel 4.2

Tabel descriptive statistics

\begin{tabular}{cccccc}
\hline \hline & $\mathrm{N}$ & Minimum & Maximum & Mean & Std. Deviation \\
\hline HONESTY & 425 & 18,80 & 74,71 & 50,00 & 10,18337 \\
EMOTIONALITY & 425 & 21,82 & 73,52 & 50,0000 & 9,96017 \\
EXTRAVERSION & 425 & 7,63 & 64,08 & 50,0000 & 10,18382 \\
AGREEBLENESs & 425 & 20,44 & 72,61 & 50,0000 & 11,61247 \\
CONSCIOUSNESS & 425 & 25,07 & 80,32 & 50,0000 & 10,27296 \\
OPENNESS & 425 & 25,72 & 74,17 & 50,0000 & 10,75220 \\
MODELING & 425 & 22,82 & 81,72 & 50,0000 & 13,94458 \\
Valid N(listwise) & 425 & & & & \\
\hline \hline
\end{tabular}

Dalam regresi logistik ada 3 hal yang dilihat yaitu, melihat besaran $\mathrm{R}$ square untuk mengetahui berapa persen (\%) varians variabel dependen yang dijelaskan oleh variabel independen, kedua melihat apakah variabel independen berpengaruh signifikan terhadap variabel dependen, kemudian terakhir melihat pengaruh masing-masing variabel independen dalam satuan logit, odds dan probabilitas.

Langkah pertama, peneliti melihat tabel 4.3 yaitu omnimbus test untuk membuktikan hipotesis nihil dalam penelitian ini. 
Tabel 4.3

Tabel Omnibus Tests

\begin{tabular}{|c|c|c|c|c|}
\hline \multicolumn{5}{|c|}{ Omnibus Tests of Model Coefficients } \\
\hline & & Chi-square & $\mathrm{Df}$ & Siq. \\
\hline Step 1 & Step & 222.104 & 7 & .000 \\
\hline & Block & 222.104 & 7 & .000 \\
\hline & Model & 222.104 & 7 & .000 \\
\hline
\end{tabular}

Selanjutnya melihat besaran $\mathrm{R}$ square untuk mengetahui berapa persen (\%) varians perilaku merokok yang dijelaskan oleh seluruh variabel independen. Dalam analisis regresi logistik, yang memiliki interpretasi mirip dengan koefisien determinasi ( $\mathrm{R}$ square) pada regresi linear dengan melihat nilai Nagelkerke R Square. Untuk tabel R square, dapat dilihat pada tabel 4.4 dan analisis model yang digunakan dalam penelitian ini dapat dilihat pada tabel 4.5 berikut:

Tabel 4.4

Tabel $R$ square

\begin{tabular}{cccc}
\hline \hline Step & -2 Log likelihood & Mode & Summary \\
\hline 1 & $\begin{array}{c}\text { Cox dan Snell R } \\
\text { Square }\end{array}$ & Nagelkerke R Square \\
\hline \hline
\end{tabular}

a. Estimation terminated at iterasion number 5 because parameter estimates changed by less than, 001 .

Tabel 4.5

Tabel hosmer and lemeshow test

\begin{tabular}{lccc}
\hline \hline \multicolumn{4}{c}{ Hosmer and Lemeshow Test } \\
\hline Step & Chi-square & $\mathrm{Df}$ & Siq. \\
\hline 1 & 8,962 & 8 & .346 \\
\hline \hline
\end{tabular}

Peneliti kemudian melihat koefisien regresi tiap independen variabel terhadap perilaku merokok. Adapun penyajiannya ditampilkan pada tabel 4.6 berikut: 
Tabel 4.6

Tabel koefisien regresi logistik

\begin{tabular}{|c|c|c|c|c|c|c|c|}
\hline \multicolumn{8}{|c|}{ Variables in the Equation } \\
\hline & & B & S.E. & Wald & Df & Sig. & $\operatorname{Exp}(B)$ \\
\hline Step $1^{a}$ & $\begin{array}{l}\text { HONESTY } \\
\text { EMOTIONALITY } \\
\text { EXTRAVESSION } \\
\text { AGREEBIENESS } \\
\text { CONSCIOSSTESS } \\
\text { OPENNESS } \\
\text { MODELING } \\
\text { Constant } \\
\end{array}$ & $\begin{array}{l}, 028 \\
-, 013 \\
-, 010 \\
, 004 \\
-, 017 \\
, 030 \\
-8,89 \\
-8,827 \\
\end{array}$ & $\begin{array}{l}016 \\
, 015 \\
, 013 \\
, 013 \\
, 014 \\
0114 \\
1,840 \\
\end{array}$ & $\begin{array}{r}3,182 \\
, 810 \\
, 603 \\
1,392 \\
4,628 \\
107,525 \\
23,015 \\
\end{array}$ & $\begin{array}{l}1 \\
1\end{array}$ & $\begin{array}{l}, 074 \\
, 368 \\
, 437 \\
, 375 \\
, 237 \\
, 031 \\
, 000 \\
\end{array}$ & $\begin{array}{l}1,028 \\
, 987 \\
1990 \\
1004 \\
1,031 \\
1,172 \\
.000 \\
\end{array}$ \\
\hline
\end{tabular}

Variable(s) entered on step 1: HONESTY, EMOTIONALITY, EXTRAVERSION,

AGREEBLENESs, CONSCIOUSNESS, OPENNESS, MODELING.

Nilai B adalah koefisien logistik yang dapat digunakan untuk membuat persamaan prediktif (sama dengan nilai $b$ pada regresi linear) dalam satuan logit. Sehingga didapatkan persamaan dari model regresi ini, yaitu: (*signifikan) Logit perilaku merokok $=-8,827+0,028$ honesty-humility $-0,013$ emotionality0,010 extraversion $+0,004$ agreeblesess $-0,017$ conscientiousness + 0,030 openness to experience ${ }^{*}+0,159$ modeling* .

Jika diketahui seseorang memiliki nilai honesty-humility 42, nilai emotionality 51, nilai extraversion 35 , nilai agreebleness 54 , nilai conscientiousness 55 , nilai openness to experience 58 , dan nilai modeling 65 , maka nilai odds yang dihasilkan adalah:

$$
\begin{aligned}
O_{i} & =\mathrm{e}^{-8,827+0,028(42)-0,013(51)-0,010(35)+0,004(54)-0,017(55)+0,030(58)+0,159(65)} \\
& =2,692
\end{aligned}
$$

Artinya, individu dengan kriteria yang disebutkan di atas memiliki peluang 2,692 kali untuk merokok dibanding tidak merokok.

Probabilitas dapat menunjukkan peluang terjadinya perilaku merokok dibandingkan tidak terjadinya perilaku merokok dengan persamaan:

$$
\text { Probabilitas merokok }=\frac{\text { odds merokok }}{1+\text { Odds merokok }}
$$

Dari persamaan nomor 5 , peneliti dapat menghitung peluang terjadinya perilaku merokok individu dilihat dari nilai keseluruhan variabel independen seperti pada contoh 1 dan persamaan 3 , sehingga didapatkan hasil sebagai berikut:

Probabilitas merokok $=\frac{2,692}{1+2,692}=0,729$

Artinya, peluang seseorang yang memiliki nilai honesty-humility 55, nilai emotionality 34, nilai extraversion 41, nilai agreebleness 52, nilai conscientiousness 48, nilai openness to experience 80 , dan nilai modeling 78 untuk merokok 0,729 atau $72,9 \%$. Nilai 72,9\% ini disebut juga nilai predicted probability. 
Proporsi varians masing-masing variabel independen dapat dilihat pada tabel 4.7 berikut:

Tabel 4.7

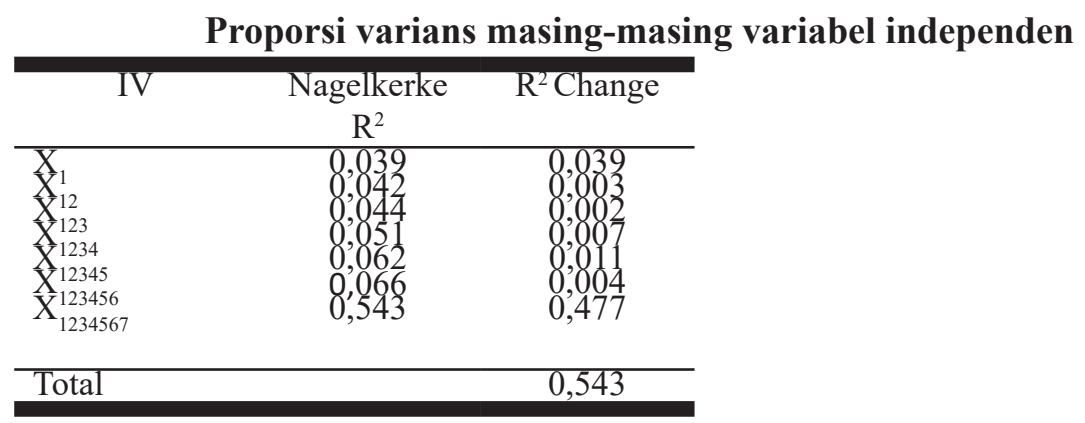

Dari kedelapan variabel independen tersebut dapat dilihat variabel manakah yang memberikan sumbangan paling besar terhadap variabel dependen dilihat dari besarnya nilai $\mathrm{R}^{2}$ change. Semakin besar nilai $\mathrm{R}^{2}$ change maka semakin banyak sumbangan yang diberikan terhadap variabel dependen. Dari tabel 4.7 dapat diketahui variabel independen yang memberikan sumbangan terbesar adalah variabel modeling dengan $\mathrm{R}^{2}$ change 0,477 , lalu honesty-humility memberikan sumbangan dengan nilai $\mathrm{R}^{2}$ change 0,039 , kemudian conscientiousness dengan nilai $\mathrm{R}^{2}$ change 0,011 , lalu agreebleness memberikan sumbangan dengan nilai $\mathrm{R}^{2}$ change 0,007 , selanjutnya openness to experience memberikan sumbangan dengan nilai $\mathrm{R}^{2}$ change 0,004 , lalu emotionality memberikan sumbangan dengan nilai $\mathrm{R}^{2}$ change 0,003 , sedangkan extraversion hanya memberikan sumbangan dengan nilai $\mathrm{R}^{2}$ change sebesar 0,002 .

\section{Kesimpulan}

\section{KESIMPULAN DAN SARAN}

Berdasarkan hasil uji hipotesis penelitian, maka peneliti dapat mengambil kesimpulan yaitu ada pengaruh yang signifikan dari honesty-humility, emotionality, extraversion, agreebleness, conscientiousness, openness to experience dan modeling teman sebaya terhadap perilaku merokok pada remaja usia sekolah. Dilihat dari proporsi seluruh varians, logit perilaku merokok yang dipengaruhi variabel independen adalah sebesar 54,3\%.

\section{Saran}

Pada penelitian selanjutnya diharapkan menggunakan variabel self-efficacy dan self-esteem yang diharapkan agar mendapatkan hasil yang lebih signifikan dan menggunakan kepribadian dari Eysenck yang diharapkan mampu menjelaskan lebih baik mengenai perilaku merokok pada remaja usia sekolah sehingga memberikan hasil yang lebih signifikan. 


\section{DAFTAR PUSTAKA}

Ashton, M. C., \& Lee, Kiboem. (2002). Six Independent Factors Of Personality Variation: A Response To Saucier. Europeans journals of personality, 16, 63-75.

Aston, M. C.\& Lee, Kibeom (2007). Empirical, Theoretical and Practical Advantages of the HEXACO Model of Personality Structure. Pers Soc Psychol, 11; 150.

Atmojo, Setyo Eko. (2013).Pembelajaran IPA Berbasis Konseling Untuk Membentuk Pemahaman Tentang Pubertas Pada Siswa Sekolah Dasar. Yogyakarta: FKIP Universitas PGRI.

DEPKES RI. (2012). Anak dan Anak Rentan Menjadi Perokok Pemula. Diakses pada 10 Juni 2014 dalam http://www.depkes.go.id/index. php? $\mathrm{vw}=2 \& \mathrm{id}=2050$

Fayombo, G., (2010). The Relationship between Personality Traits And Psychological Resilience Among The Caribbean Adolenscents. International Journal of psychological studies. Vol. 2 No. 2.

Hames, K. \& Parker, J. (2008). Personality And Social Differences Of Cigarette Smoking Among College Students. Research Journal, Volume I.

Komalasari, D. \& Helmi, A.F. (2000). Faktor-Faktor Penyebab Perilaku Merokok Pada Anak. Jurnal Psikologi Universitas Gadjah Mada, Yogyakarta.

Lee, Kibeom dkk. (2008). Predicting integrity with the HEXACO personality model: Use of self- and observer reports. Journal of Occupational and Organizational Psychology, 81, 147-167.

Malouff, J. M., Einar, B. T., Nicola, S. S. (2006). The Five-Factor Model Of Personality And Smoking: A Meta-Analysis. Journal of Drug Education, Vol. 36(1) 47-58.

Messwati, 2008. Perilaku Merokok di Kalangan Anak. Diakses pada 10 Juni 2014 dalam http://thesis.binus.ac.id/Asli/Bab1/2011-1-00003-PL\%20 BAB\%201.pdf

Munafo, M. R., Jessica, I. Z., Taane, G. M.C. C. (2007). Personality and smoking status: A meta-analysis. Nicotine \& Tobacco Research, Vol. 9, 405-413.

Notoatmodjo, S.(2010). Promosi kesehatan: Teori dan Aplikasi. Jakarta: Rineka Cipta.

Sarafino, E. P. (2011). Health Psychology: Biopsychosocial Interactions $\left(5^{\text {th }}\right.$ ed). USA: John Wiley \& Sons.

Umar, J. (2011). Bahan ajar psikometri. Tidak dipublikasikan.

Von Ah, D., dkk., (2005). Factors Related to Cigarette Smoking Initiation and Use among College Students. Tobacco Induced Diseases, Vol. 3, No. 1:2740.

Wahyono, Bambang\& Maharani, Chatila. (2010). Peningkatan Pengetahuan Tentang Bahaya Merokok Pada Siswa Sltp Negeri Limbangan Kendal. 
Semarang: Fakultas Ilmu Keolahragaan Universitas Negeri Semarang. Santrock, J.W. Adolescence. Remaja. Edisi 11. Benedictine Widyasinta (terj). (2007). Jakarta: Erlangga.

Shapley, H. (2011). Celebrity worship is a big part of our culture but is it a good thing?. Diunduh tanggal 20 November 2014 dari http://www.haleyshapley. com/yahoo site admin/assets/docs/Celeb Worship.295185618.pdf 